\title{
An engineering approach to dry friction behaviour of numerous engineering plastics with respect to the mechanical properties
}

\author{
G. Kalácska* \\ *Institute for Mechanical Engineering Technology, Faculty of Mechanical Engineering, Szent István University, H-2100 \\ Gödöllö, Hungary
}

Received 5 August 2012; accepted in revised form 13 October 2012

\begin{abstract}
Twenty-one different commercial-grade engineering polymers, including virgin and composite types, were selected for testing, based on mechanical engineering practices. Three groups were formed according to typical applications: 1) Sliding machine element materials; 2) Mechanically load-carrying machine element materials that are often subjected to friction and wear effects; and 3) Additional two amorphous materials used as chemically resistant materials that have rare sliding load properties. The friction running-in state was tested using a dynamic pin-on-plate test rig. During steady-state friction tests, two $p v$ regimes $\left(0.8\right.$ and $\left.2 \mathrm{MPa} \cdot \mathrm{ms}^{-1}\right)$ were analysed by a pin-on-disc test system. Based on the measured forces on ground structural steel, surface friction coefficients were calculated and analysed with respect to the mechanical effects of friction. The friction results were evaluated by the measured mechanical properties: yield stress, Shore D hardness, Young's modulus and elongation at the break.

The three material groups exhibited different trends in friction with respect to changing mechanical properties. Linear (with varying positive and negative slopes), logarithmic and exponential relationships were observed, and occasionally there were no effects observed. At steady-state friction, the elongation at the break had less effect on the friction coefficients. The dynamic sliding model, which correlates better to real machine element applications, showed that increasing hardness and yield stress decreases friction. During steady-state friction, an increase in $p v$ regime often changed the sign of the linear relationship between the material property and the friction, which agrees with the frictional theory of polymer/steel sliding pairs.
\end{abstract}

Keywords: material testing, friction of plastics, mechanical properties

\section{Introduction}

The effect of friction on the wear of engineering polymers is a complex and intricate consequence of the micro- and macroscopic interactions of surfaces moving against one another. Friction and the resulting wear are not material properties of plastics; therefore, they cannot be reduced to tabular data of material characteristics that can be found in relevant manuals. Determining friction and the resulting wear involves more complex examination because they are characteristics of a frictional contact system where the effects of the entire system are manifest. Precise knowledge of system conditions is essential to evaluate the friction and resulting wear [1]. These materials have system-dependent tribological behaviour; thus, trends can be defined at a given condition, and the materials can be compared. The system approach is well-known from the literature [2,

\footnotetext{
${ }^{*}$ Corresponding author, e-mail: kalacska.gabor@gek.szie.hu

(c) BME-PT
} 
3] and was published in the former German standard DIN 50322 [4] in the section on wear test categories.

The tribology of polymeric materials involves complicated frictional systems where the deformation and thermal effects of the contact zone, time-dependent stress states, surface energy characteristics, etc., play important roles [5]. Because polymers have gained a more accepted position among industrial materials, plastics are no longer second-class materials. They have become elements of real machines, and the need for tribological knowledge has risen from the many frictional applications now involving plastics. Some general knowledge of polymers and composites has been published summarising global experiences, e.g., wear mechanism and particle detachment, transfer films, and the effects of reinforcements and lubricants [6-8]. Large numbers of papers have addressed a given material family, e.g., polyamides, under different conditions, such as abrasive effects [9-12]. With respect to dry or lubricated conditions of polymer sliding, the principles of some commonly used material families have been tested, and the role of adhesion and surface energy has been discussed [13, 14]. There have been initiatives to find the correlation between the wear behaviour and the mechanical properties of polymers, but difficult or weak correlations have been found, primarily because of the limited condition of the wear systems and the selected material families [15-18]. In recent years, research has focused on the surface-modified engineering polymers and nano-composites because of new technology that enhances the tribological behaviour by changing the molecular or matrix structure to change the surface or bulk properties [19-21].
In the tribological literature of engineering polymers, most of the research is related to materials, material families or operating conditions. Little information is available regarding mechanical engineering applications to compare the different material families and typically applied material groups. The present research investigates the frictional behaviour of several engineering polymers in sliding and mechanical load-carrying applications to determine trends between the mechanical properties and friction.

\section{Selected materials and their mechanical properties}

The engineering plastic samples tested were machined from commercially available semi-finished stock shapes, namely, from rods. The rods were manufactured by Sustaplast $\mathrm{GmbH}$ (Germany), Quadrant EPP (Belgium), Ensinger GmbH (Germany), Teraglobus Ltd. (Hungary) and Quattroplast Ltd. (Hungary), and they were procured from Teraglobus (Hungary) and Quattroplast (Hungary). The mechanical properties were measured according to the appropriate standards (tensile MSZ EN ISO 527-1 and hardness MSZ EN ISO 868: 2003). Then, the mechanical and tribological test samples were machined. After one week of conditioning in the laboratory $\left(23^{\circ} \mathrm{C} / 60 \% R H\right)$, mechanical measurements were repeated five times and averaged. The measured data were not equal to the producers' indicative values, not even for the conditioned polyamide-type materials. At Teraglobus Ltd.'s laboratory (Instron 3366 for tensile tests, THS-180 hardness tester for Shore D), the following properties were determined: yield stress $(R)$, Young's modulus $(E)$, elongation at break $(A)$ and

Table 1. Selected materials

\begin{tabular}{|c|c|c|c|}
\hline $\begin{array}{l}\text { Simplified name } \\
\text { (code) }\end{array}$ & Known composition & $\begin{array}{l}\text { Simplified name } \\
\text { (code) }\end{array}$ & Known composition \\
\hline PTFE & PTFE unmodified & PETP & PETP unmodified \\
\hline PTFE/graphite & PTFE + (graphite) & PETP TF & PETP+(PTFE) \\
\hline UHMW-PE HD500 & UHMW-PE HD500 unmodified 1 & POM C & POM C unmodified \\
\hline UHMW-PE HD1000 & UHMW-PE HD1000 unmodified & PPS HPV & PPS+(GF+oil) \\
\hline PA 4.6 & PA 4.6 unmodified & PSU & PSU unmodified \\
\hline PA6E & PA6 Extruded, unmodified & PES & PES unmodified \\
\hline "PA6G(Mg) & *PA6G(Mg) cast, unmodified & PVDF & PVDF unmodified \\
\hline *PA6G(Mg)/oil & "PA6G(Mg)+(oil) & PEEK & PEEK unmodified \\
\hline${ }^{* *} \mathrm{PA} 6 \mathrm{G}(\mathrm{Na}) / \mathrm{MoS}_{2}$ & ${ }^{* *} \mathrm{PA} 6 \mathrm{G}(\mathrm{Na})+\left(\mathrm{MoS}_{2}\right)$ & PEEK GF & PEEK+(GF) \\
\hline${ }^{* *} \mathrm{PA} 6 \mathrm{G} / \mathrm{PE}$ & ${ }^{* *} \mathrm{PA} 6 \mathrm{G}(\mathrm{Na})+(\mathrm{PE})$ & PEEK Mod & PEEK+(CF+PTFE+graphite $)$ \\
\hline PA 66 GF30 & PA $66+(\mathrm{GF})$ & & \\
\hline
\end{tabular}

${ }^{*} \mathrm{Mg}$ catalytic casting process

${ }^{* *} \mathrm{Na}$ catalytic casting process 
Table 2. Material groups and mechanical properties (measured and averaged values)

\begin{tabular}{|c|c|c|c|c|}
\hline Simplified name & $\begin{array}{c}\mathbf{R} \\
{[\mathrm{MPa}]}\end{array}$ & $\begin{array}{c}\mathbf{A} \\
{[\%]}\end{array}$ & $\begin{array}{c}\mathbf{E} \\
{[\mathrm{MPa}]}\end{array}$ & $\begin{array}{c}\text { H } \\
\text { [Shore D] }\end{array}$ \\
\hline \multicolumn{5}{|c|}{ Sliding materials (Material Group 1) } \\
\hline PTFE & 30.9 & 384 & 544.8 & 55.2 \\
\hline PTFE/graphite & 33.1 & 222 & 606.5 & 58.6 \\
\hline UHMW-PE HD500 & 28.4 & 585 & 1350.8 & 66.0 \\
\hline UHMW-PE HD1000 & 20.6 & 298 & 744.6 & 62.3 \\
\hline PA6G(Mg)/oil & 52.5 & 58 & 1808.2 & 81.5 \\
\hline $\mathrm{PA} 6 \mathrm{G}(\mathrm{Na}) / \mathrm{MoS}_{2}$ & 65.5 & 53 & 2020.4 & 82.1 \\
\hline $\mathrm{PA} 6 \mathrm{G} / \mathrm{PE}$ & 45.1 & 78 & 1811.4 & 77.4 \\
\hline PETP TF & 75.3 & 12 & 2806.3 & 82.8 \\
\hline PPS HPV & 74.1 & 8 & 3712.8 & 80.1 \\
\hline PEEK Mod & 121.5 & 5 & 7808.2 & 85.3 \\
\hline PETP & 85.6 & 19 & 2991.7 & 83.3 \\
\hline \multicolumn{5}{|c|}{ Load-carrying materials (Material group 2) } \\
\hline PA 4.6 & 56.5 & 106 & 11288.8 & 78.5 \\
\hline PA6E & 47.2 & 81 & 1603.6 & 79.2 \\
\hline PA6G(Mg) & 57.9 & 69 & 2034.4 & 82.3 \\
\hline PA 66 GF30 & 89.2 & 19 & 3900.8 & 84.7 \\
\hline POM C & 74.5 & 34 & 2996.4 & 83.6 \\
\hline PVDF & 58.3 & 30 & 2110.5 & 81.4 \\
\hline PEEK & 108.4 & 25 & 3904.6 & 87.2 \\
\hline PEEK GF & 156.9 & 5 & 9688.5 & 89.1 \\
\hline \multicolumn{5}{|c|}{ Other amorphous (Material Group 3) } \\
\hline PSU & 77.8 & 19 & 2608.5 & 83.1 \\
\hline PES & 87.1 & 16 & 2689.3 & 82.6 \\
\hline
\end{tabular}

Shore D hardness $(H)$. Table 1 shows the materials and the published compositions, while Table 2 shows the measured properties in the three material groups: a) sliding, b) load-carrying and c) other amorphous structural materials. The selected sliding materials are typically used for slide bearings, trust washers, sliding supports and pads, gears and worms, where $p v$ (normal load multiplied by sliding speed) is the basis of the construction and the design. The plastics of the second group often face significant mechanical loads in addition to friction effects. The third group (amorphous PES and PSU) is rarely subjected to frictional loads, although it is possible. The target applications for PES and PSU focus mainly on chemical and heat resistance. The knowledge, experiences and suggestions for engineering solutions of the main producers (Quadrant, Ensinger, and Röchling) serve as the basis for the grouping.

\section{Experimental design}

\subsection{Pin-on-disc and dynamic pin-on-plate test systems}

To measure the friction in comparative test systems, the pin-on-disc test method and the dynamic pinon-plate test system are selected, using classical

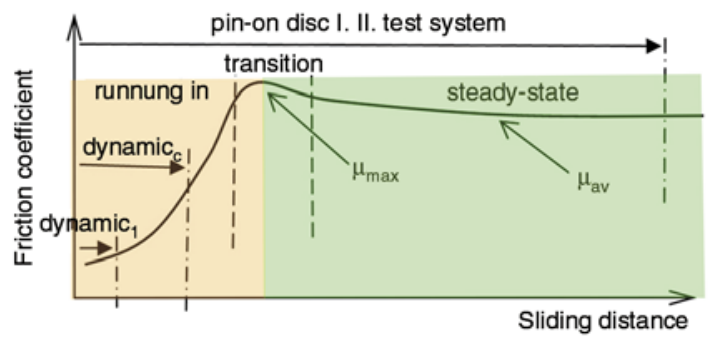

Figure 1. Friction stages between polymer/steel pairs and the placement of pin-on-disc and dynamic pinon-plate test systems.

dynamic $_{1}$ : 1 cycle of sliding path test within the running-in phase

dynamic $_{c}$ : Complete (5 cycles of sliding path) dynamic sliding test

pin-on-disc I, II test systems: After the running-in period, $\mu$ max and $\mu$ av are measured

(not overloaded) polymer/steel friction processes [1], as shown in Figure 1 [22]. The load and sliding speed values of the test systems correspond to dry slide bearing applications of engineering plastics with high safety factors.

After starting, the friction coefficient increases during the running-in period. During the running-in period, the contact zone is being reformed and restructured (e.g., the topographical and surface layers), strongly influencing the steady-state friction behaviour and the real working lifetime. After the running-in period, a transient zone appears where the maximum coefficient of friction can be measured. During the running-in, a polymeric film forms on the micro-topography of the steel surface. An increasing force is then required to continue the sliding process because of the interfering mechanical cutting and forming of the contact zone and adhesive effects between the materials. As the polymer film forms, the adhesive component of the friction increases from the polymer/polymer contact, which has stronger adhesion than the steel/polymer contact. At the maximum point of friction in the transition zone, the re-adhesion process of the polymer film starts to provide a dynamic balance during further sliding, resulting in what is termed the steady-state of friction (force and coefficient). This phenomenon is shown in Figure 2 [22].

As shown in Figure 1, the pin-on-disc measuring system evaluates the friction process at steady-state in two $p v$ regimes, characterising the $\mu_{\max }$ and $\mu_{\mathrm{av}}$ (average). The $p v$ regimes set for the tests are typical for the normal application of plastic machine elements having a high safety factor. The difference 


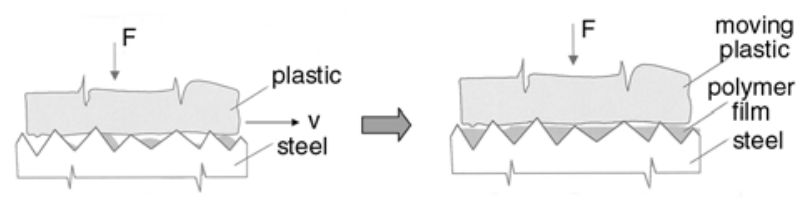

Figure 2. Running-in (left) and steady-state friction (right) with dynamic balance of polymer film adhesion and re-adhesion $\left(\mu_{\mathrm{av}}\right)$

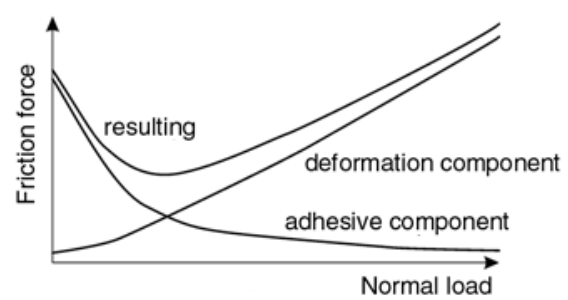

Figure 3. Theory of friction components

between the two systems is the normal load; the sliding speed is held constant. During the evaluation, it is important to know how the change in normal load influences the frictional force and coefficient $[1,22$, 23] (Figure 3). According to the theory of friction $[5,23]$, the dry friction force, $F_{\mathrm{f}}$, is equal to the sum of the adhesion and the deformation components, $F_{\mathrm{f}}=F_{\mathrm{a}}+F_{\mathrm{d}}$. The special case at low loads, when the deformation component may be orders of magnitude smaller than the adhesion component $\left(F_{\mathrm{a}}>>F_{\mathrm{d}}\right)$, leads to the relation $F_{\mathrm{f}} \approx F_{\mathrm{a}}$. The research results will show that the set pv-s yields near-optimum (Figure 3) friction values for most of the selected materials.

The dynamic pin-on-plate test system was utilised during the running-in period. Dynamic ${ }_{1}$ represents one sliding cycle of the programmed sliding path, while dynamic $_{\mathrm{c}}$ refers to the complete dynamic test program, i.e., five repeated cycles of the programmed sliding path. The dynamic modelling method and test rig were developed at Szent István University, where a better laboratory model of the real dynamic effects of the machine elements could be made. The details of the method have been described previously [24].

\subsection{Test conditions}

Table 3 summarises the test conditions.

The pin-on-disc measurements (Figure 4) were performed according to wear test category VI of the German standard DIN 50322 [4]. The fixed plastic samples, with a diameter of $6 \mathrm{~mm}$ and a height of $15 \mathrm{~mm}$, were used as pins for the rotating S235 steel disc, which has a finely ground surface with an average roughness of $R_{\mathrm{a}}=0.05-0.1 \mu \mathrm{m}$. The pin was positioned on the disc for each experiment at a radius of $100 \mathrm{~mm}$. During the measurements, the following parameters were simultaneously measured: the coefficient of friction $(\mu)$, based on the measured forces $\left(F_{\mathrm{x}}\right.$ and $\left.F_{\mathrm{y}}\right)$, and the wear, characterised by the vertical displacement of the pin holder $(d)$ and the temperature close to contact $(T)$. The friction results are presented below.

During the dynamic friction tests (dynamic pin-onplate), a moving plastic sample pin with a diameter of $4 \mathrm{~mm}$ moved along the programmed path (Figure 5) with a dynamic change of normal load and speed values, combined with inertial effects at the bends. The dynamic test completed the full path five times (five cycles) at five average loads and five speeds. During the evaluation, the first cycle is

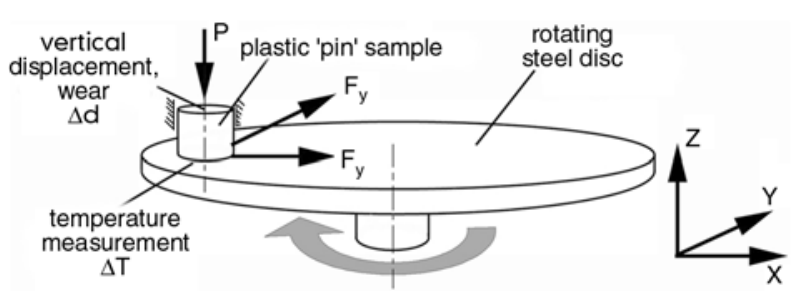

Figure 4. Pin-on-disc setup for steady-state friction measurements

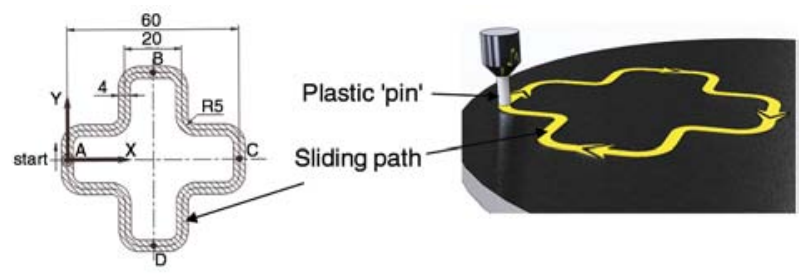

Figure 5. Programmed dynamic sliding path of plastic samples on the fixed steel plate

Table 3. Test conditions

\begin{tabular}{|l|c|c|c|}
\hline & $\begin{array}{c}\text { Pin-on-disc I } \\
\left(\mathbf{p v}=\mathbf{0 . 8} \mathbf{~ M P a} \cdot \mathbf{m s}^{-\mathbf{1}}\right)\end{array}$ & $\begin{array}{c}\text { Pin-on-disc II } \\
\left(\mathbf{p v}=\mathbf{2} \mathbf{~ M P a} \cdot \mathbf{m s}^{-\mathbf{1}}\right)\end{array}$ & $\begin{array}{c}\text { Pin-on-plate dynamic tests } \\
\left(\mathbf{p v} \text { regime 0-8 } \mathbf{~ M P a} \cdot \mathbf{m s}^{-\mathbf{1}}\right)\end{array}$ \\
\hline Sliding speed $[\mathrm{m} / \mathrm{s}]$ & 0.4 & 0.4 & $0-0.4$ \\
\hline Period of test $[\mathrm{h}]$ & 0.75 & 0.75 & $1-5$ cycles \\
\hline Surface load $[\mathrm{MPa}]$ & 2 & 5 & $0-20$ \\
\hline Friction path radius $[\mathrm{mm}]$ & 100 & 100 & Dynamic program path \\
\hline Disk surface roughness $[\mu \mathrm{m}]$ & $R_{\mathrm{a}} 0.05-0.1$ & $R_{\mathrm{a}} 0.05-0.1$ & $R_{\mathrm{a}} 0.05-0.1$ \\
\hline Ambient temperature $\left[{ }^{\circ} \mathrm{C}\right]$ & 23 & 23 & 23 \\
\hline
\end{tabular}


illustrated separately (as shown in Figure 1) from the averaged values of the completed five cycles.

\section{Results and discussion}

\subsection{Comparison of the measured friction data} The friction results are summarised in Table 4 (by test system) and illustrated in the graphs in Figures 6-8. In Figure 6, the dynamic pin-on-plate results are summarised. The data show that the short

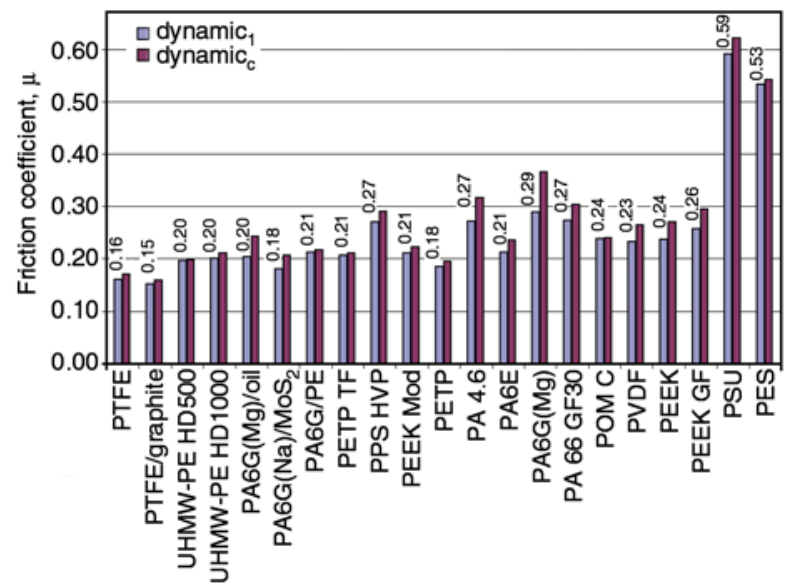

Figure 6. Dynamic pin-on-plate friction results from the sliding cycle 1 and completed full path (the latter values are indicated) sliding distances result in relatively low friction values, characteristic of the running-in period of friction, as illustrated in Figure 1.

Among the machine element materials, PA6G/PE, PETP and the PETP/PTFE composites experienced a sudden change in friction, implying the rapid formation of a polymer film that changed the properties of the mechanical deformation, mechanical cutting and adhesion in the contact zone.

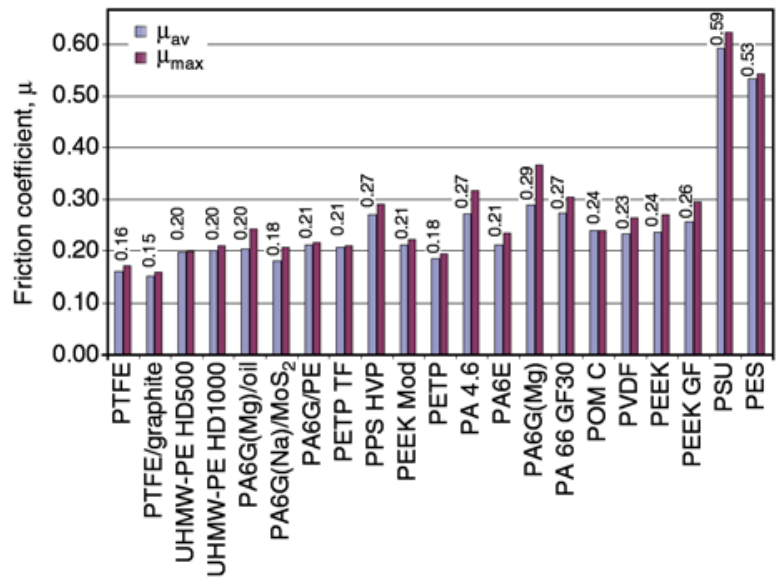

Figure 7. Pin-on-disc results from test system I $(p v=$ $0.8 \mathrm{MPa} \cdot \mathrm{ms}^{-1}$, numbers indicate $\mu_{\mathrm{av}}$ )

Table 4. Measured friction values in different test systems

\begin{tabular}{|c|c|c|c|c|c|c|}
\hline & \multicolumn{2}{|c|}{ Dynamic pin-on-plate } & \multicolumn{2}{|c|}{ Pin-on-disc I } & \multicolumn{2}{|c|}{ Pin-on-disc II } \\
\hline & $\mu_{\mathrm{av}}$ cycle 1 & $\mu_{\mathrm{av}}$ complete & $\mu_{\mathrm{av}}$ & $\mu_{\max }$ & $\mu_{\mathrm{av}}$ & $\mu_{\max }$ \\
\hline \multicolumn{7}{|c|}{ Sliding materials (Material Group 1) } \\
\hline PTFE & 0.10 & 0.13 & 0.16 & 0.17 & 0.17 & 0.18 \\
\hline PTFE/graphite & 0.11 & 0.13 & 0.15 & 0.16 & 0.18 & 0.18 \\
\hline UHMW-PE HD500 & 0.07 & 0.09 & 0.20 & 0.20 & 0.19 & 0.20 \\
\hline UHMW-PE HD1000 & 0.08 & 0.09 & 0.20 & 0.21 & 0.20 & 0.20 \\
\hline PA6G(Mg)/oil & 0.07 & 0.10 & 0.20 & 0.24 & 0.16 & 0.23 \\
\hline $\mathrm{PA} 6 \mathrm{G}(\mathrm{Na}) / \mathrm{MoS}_{2}$ & 0.06 & 0.10 & 0.18 & 0.21 & 0.17 & 0.18 \\
\hline PA6G/PE & 0.10 & 0.14 & 0.21 & 0.22 & 0.21 & 0.22 \\
\hline PETP TF & 0.06 & 0.14 & 0.21 & 0.21 & 0.18 & 0.18 \\
\hline PPS HPV & 0.06 & 0.09 & 0.27 & 0.29 & 0.24 & 0.25 \\
\hline PEEK Mod & 0.06 & 0.08 & 0.21 & 0.22 & 0.19 & 0.19 \\
\hline PETP & 0.06 & 0.13 & 0.18 & 0.19 & 0.18 & 0.18 \\
\hline \multicolumn{7}{|c|}{ Load-carrying materials (Material group 2) } \\
\hline PA 4.6 & 0.10 & 0.11 & 0.27 & 0.32 & 0.30 & 0.31 \\
\hline PA6E & 0.09 & 0.10 & 0.21 & 0.23 & 0.19 & 0.23 \\
\hline PA6G(Mg) & 0.08 & 0.10 & 0.29 & 0.37 & 0.25 & 0.33 \\
\hline PA 66 GF30 & 0.06 & 0.09 & 0.27 & 0.30 & 0.21 & 0.26 \\
\hline POM C & 0.07 & 0.08 & 0.24 & 0.24 & 0.20 & 0.20 \\
\hline PVDF & 0.09 & 0.10 & 0.23 & 0.26 & 0.28 & 0.33 \\
\hline PEEK & 0.06 & 0.08 & 0.24 & 0.27 & 0.28 & 0.29 \\
\hline PEEK GF & 0.06 & 0.08 & 0.26 & 0.29 & 0.29 & 0.32 \\
\hline \multicolumn{7}{|c|}{ Other amorphous (Material Group 3) } \\
\hline PSU & 0.11 & 0.18 & 0.59 & 0.62 & 0.55 & 0.65 \\
\hline PES & 0.13 & 0.18 & 0.53 & 0.54 & 0.54 & 0.58 \\
\hline
\end{tabular}

All the data are valid for dry sliding against a ground S235 steel surface under the defined system characteristics. 
The summary of the pin-on-disc I measurements is shown in Figure 7 . The relatively low $\left(0.8 \mathrm{MPa} \cdot \mathrm{ms}^{-1}\right)$ $p v$ regime resulted in a moderate difference between the material groups, with the exception of the amorphous materials (PES and PSU). The stabilised friction coefficients of material group 1 are $5-10 \%$ lower than those of material group 2. In material group 1 , the difference between $\mu_{\max }$ and $\mu_{\mathrm{av}}$ is generally smaller than it is for the others, indicating a smooth transition zone (see Figures 1 and 2) with an even transfer layer. The results of increased load effects $\left(p v=2 \mathrm{MPa} \cdot \mathrm{ms}^{-1}\right)$ are measured using pinon-disc measurements and shown in Figure 8.

The pin-on-disc system II (Figure 8) test results, compared to the system I test results (Figure 7), show that most of the materials from category 1 resulted in lower or similar friction with the increased load. For those materials, e.g., PTFE, PETP/PTFE, and PA6G (Mg)/oil, the test systems worked on the left side of the friction optimum point, as shown in Figure 3. This behaviour is in agreement with friction theory $[5,23]$ and is the result of the lower surface adhesion of slidinggroup materials. Many other plastics, e.g., PA4.6 and PEEK, worked on the right side of the optimum point (Figure 3), that is, the increased load resulted in higher friction.

The friction data were evaluated as a function of the measured mechanical properties. The material groups were thus distinguished. PES and PSU were categorized in group 2 but did not follow the group trendlines, most likely because PES and PSU differ from the other tested materials not only in molecular structure but also in friction behaviour.

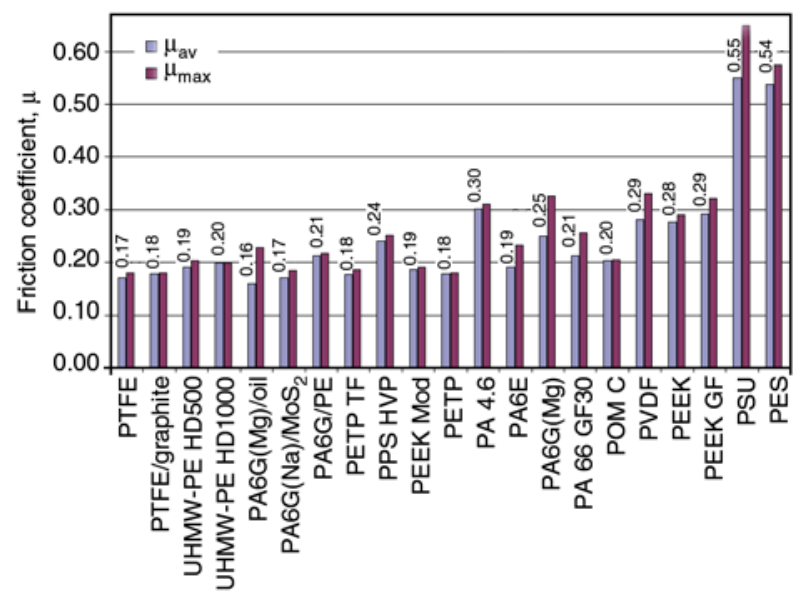

Figure 8. Pin-on-disc results from test system II ( $p v=$ $2 \mathrm{MPa} \cdot \mathrm{ms}^{-1}$, numbers indicate $\mu_{\mathrm{av}}$ )

\subsection{Friction coefficients and yield stress}

The relationship between the friction values and yield stress is shown in Figure 9.

During the running-in period, when the dynamic changes of speed and load temporarily reach the highest load $\left(p v=8 \mathrm{MPa} \cdot \mathrm{ms}^{-1}\right)$, the friction decreases with increasing yield stress (Figure 9a). A powerfunction curve is an estimate for the first cycle of the dynamic test, but the complete program (five cycles) results in too much scatter to perform a curve-fit. This trend can be explained by the role of the still-weak effects of the generated frictional heat and also by the actual size of the contact area.

Each test system shows that the group of sliding machine element materials (material group 1) offers lower friction coefficients compared to the structural and load-carrying plastics (material group 2). In the pin-on-disc test systems, the ' $R$ ' property has little effect on friction. At the lower $p v$ regime (pinon-disc I test system, $p v=0.8 \mathrm{MPa} \cdot \mathrm{ms}^{-1}$ ), ' $R$ ' does not influence the friction in the case of material group 2. For material group 1, except during the running-in period, the friction increases slightly with increasing ' $R$ ' as a result of deformation and adhesion because of the varying adhesion forces occurring in the dynamic balance of the polymer film formation with respect to the minimal deformation at low loads (Figure 9b). The elevated load in the pinon-disc II test system affects the result. ' $R$ ' has no effect on material group 1, but for material group 2, higher ' $R$ ' values cause a slight increase of friction (Figure 9c).

\subsection{Friction coefficients versus the elongation at the break}

Figure 10 shows the friction coefficients versus the elongation at the break. For the first cycle of the dynamic test system (Figure 10a), the relationship is logarithmic and linear. Higher ' $A$ ' values result in increased friction, even for material group 2. This behaviour relates to the role of adhesion: higher strain can cause higher deformation, enlarging the actual contact area. Based on the pin-on-disc test system results, the elongation at the break (' $A$ ') has a weak effect on friction. At lower loads (Figure 10b), an increase in ' $A$ ' causes a negligible decrease of friction for material group 1 and a slight increase of friction for material group 2 . 

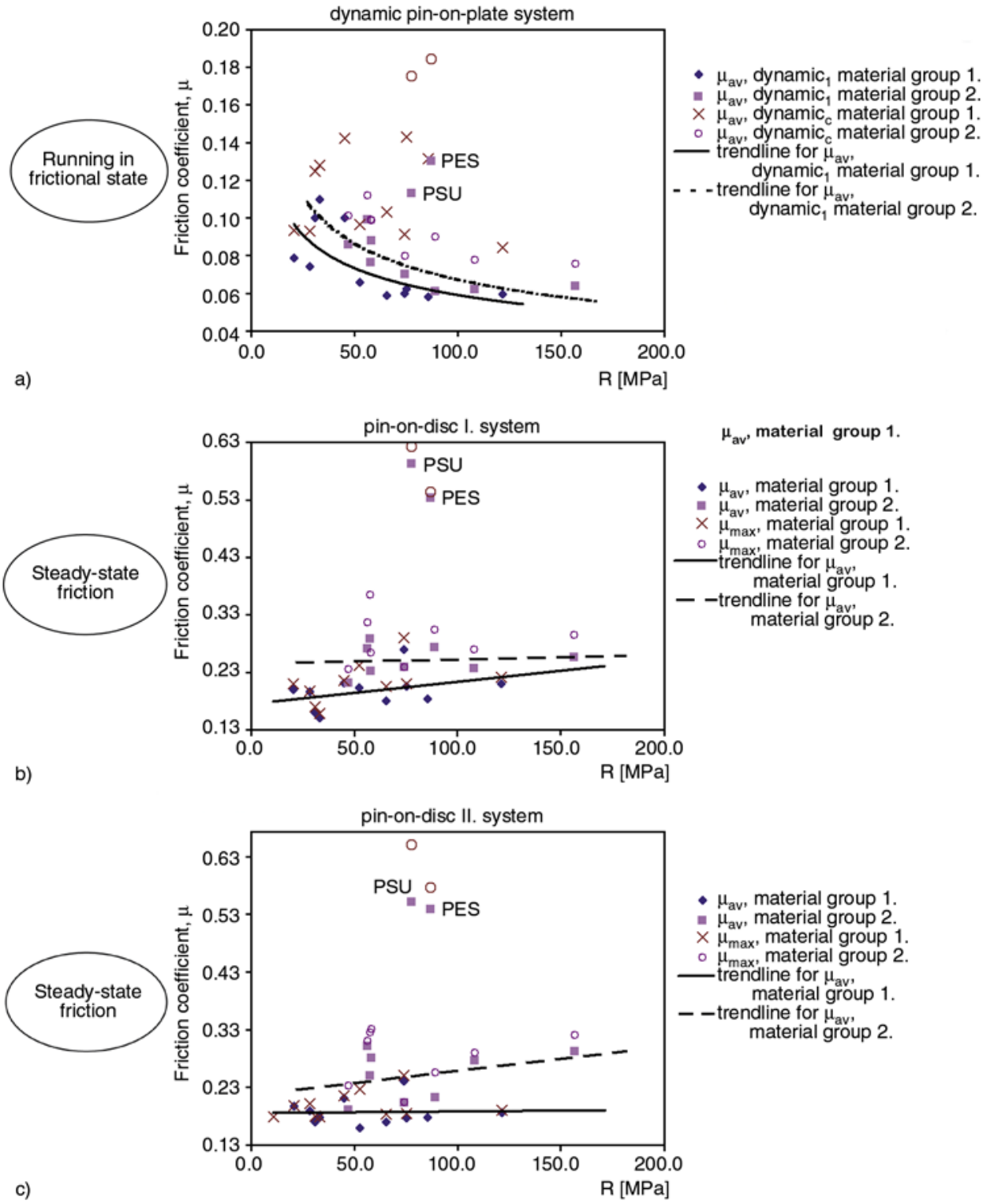

Figure 9. Friction coefficients versus yield stress, $R$ [MPa]. (a) dynamic pin-on-plate, cycle 1 and completed program, $\mu_{\mathrm{av}}$ values, (b) pin-on-disc I ( $\left.p v=0,8 \mathrm{MPa} \cdot \mathrm{ms}^{-1}\right), \mu_{\max }$ and $\mu_{\mathrm{av}}$ values, (c) pin-on-disc II $\left(p v=2 \mathrm{MPa} \cdot \mathrm{ms}^{-1}\right), \mu_{\max }$ and $\mu_{\mathrm{av}}$ values.

With the elevated loads (pin-on-disc II), no effect of ' $A$ ' on friction was observed (Figure 10c).

\subsection{Friction coefficients in the function of modulus of elasticity}

Figure 11 shows the friction coefficients versus Young's modulus. During the running-in period, there were similar results for the dynamic pin-onplate test for both material categories. An optimum ' $E$ ' value is shown for sliding and load-carrying plastics in cycle 1 . In the test system, the optimum ' $E$ ' is approximately $5000-6000 \mathrm{MPa}$. This value is system-dependent as it depends on the surface roughness, the metallic composition of the mating surface and other system features (e.g., temperature). The test system was designed using typical engineering solutions. After five cycles, near the transition, the scatter in the data (Figure 11a) is too large to define any specific trend.

During steady-state friction, the pin-on-disc measurements primarily show a linear relationship between the friction and Young's modulus (' $E$ '). The relationship changes with the load level of the systems. For pinon-disc I, an increase in ' $E$ ' causes a larger increase in friction for material group 1 than for material group 2 (Figure 11b). At low load levels, this phenomenon may be due to adhesive effects from the higher surface energy, in accordance with the adhe- 


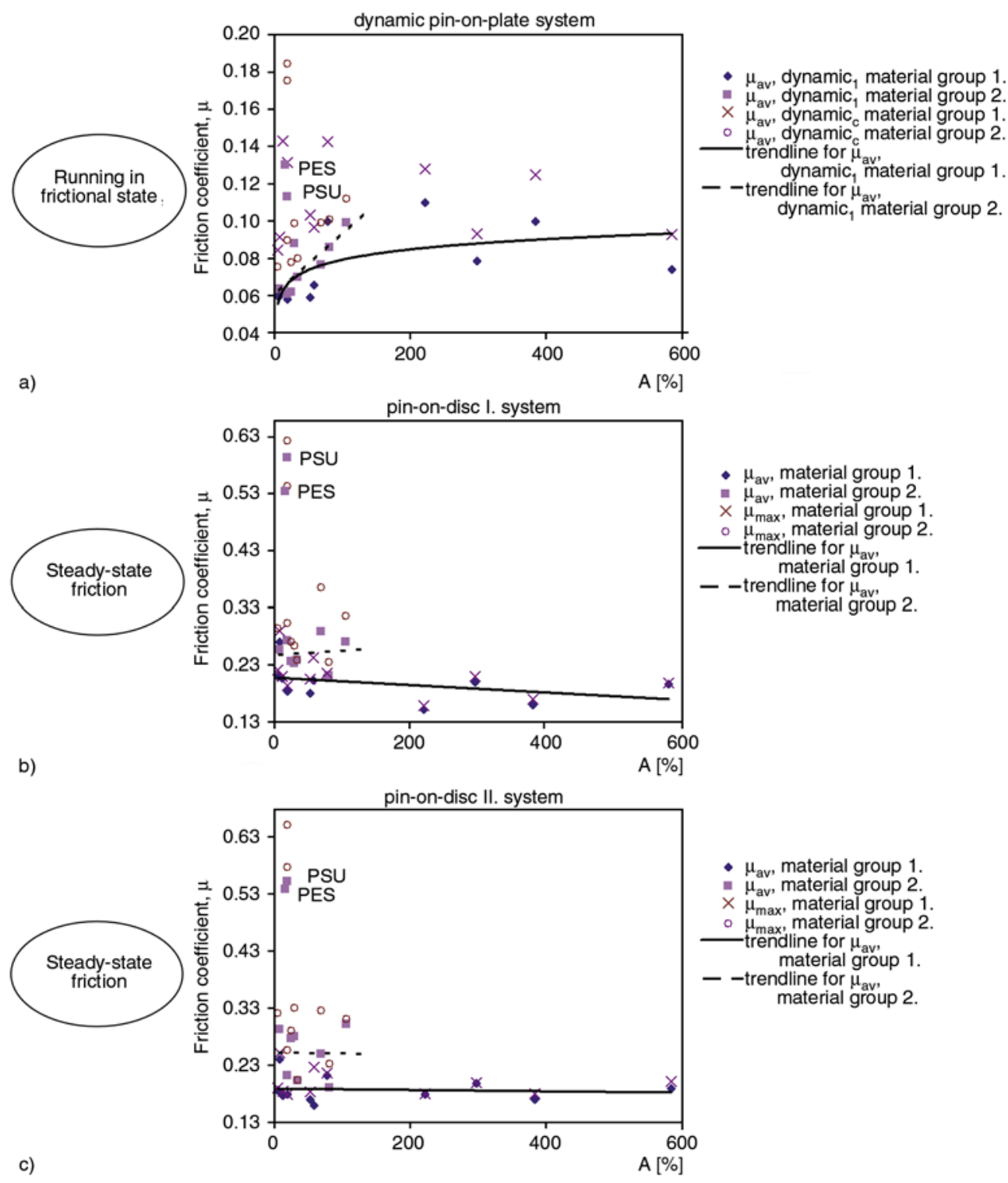

Figure 10. Friction coefficients versus elongation at break, $A[\%]$. (a) dynamic pin-on-plate, cycle 1 and completed program, $\mu_{\mathrm{av}}$ values, (b) pin-on-disc I $\left(p v=0,8 \mathrm{MPa} \cdot \mathrm{ms}^{-1}\right), \mu_{\max }$ and $\mu_{\mathrm{av}}$ values, (c) pin-on-disc II $\left(p v=2 \mathrm{MPa} \cdot \mathrm{ms}^{-1}\right)$, $\mu_{\max }$ and $\mu_{\mathrm{av}}$ values.

sive theory of friction $[5,23]$. It is known that in PEEK or PEEK composites, both the ' $E$ ' value and the surface energy are higher than in other materials, such as UHMW-PE. The increased load level in the pin-on-disc II tests shows different trends between friction and ' $E$ ', as well (Figure 10c). The deformation and adhesion work together to form the resulting friction changes for material group 2 but provide no significant change for material group 1 .

\subsection{Friction coefficients plotted against Shore D hardness}

Figure 12 shows the relationship between the Shore D hardness and friction. The dynamic tests show that during the early stage of friction, the increased hardness is advantageous and results in lower friction in both material groups because of lower deformation and smaller actual contact area, resulting in lower mechanical and adhesive forces. Nearing the transition zone (Figure 1) during the complete dynamic test, the forming polymer layer and its adhesive effect change the dynamic, and the scatter in the data (Figure 12a) is too large to indicate a trend.

The steady-state friction measurements revealed that the role of the surface hardness changes. At lower loads (Figure 12b), the hardness has no significant effect on the observed friction in material group 2, but a slight increase of friction with hardness in material group 1 reflects the different adhe- 

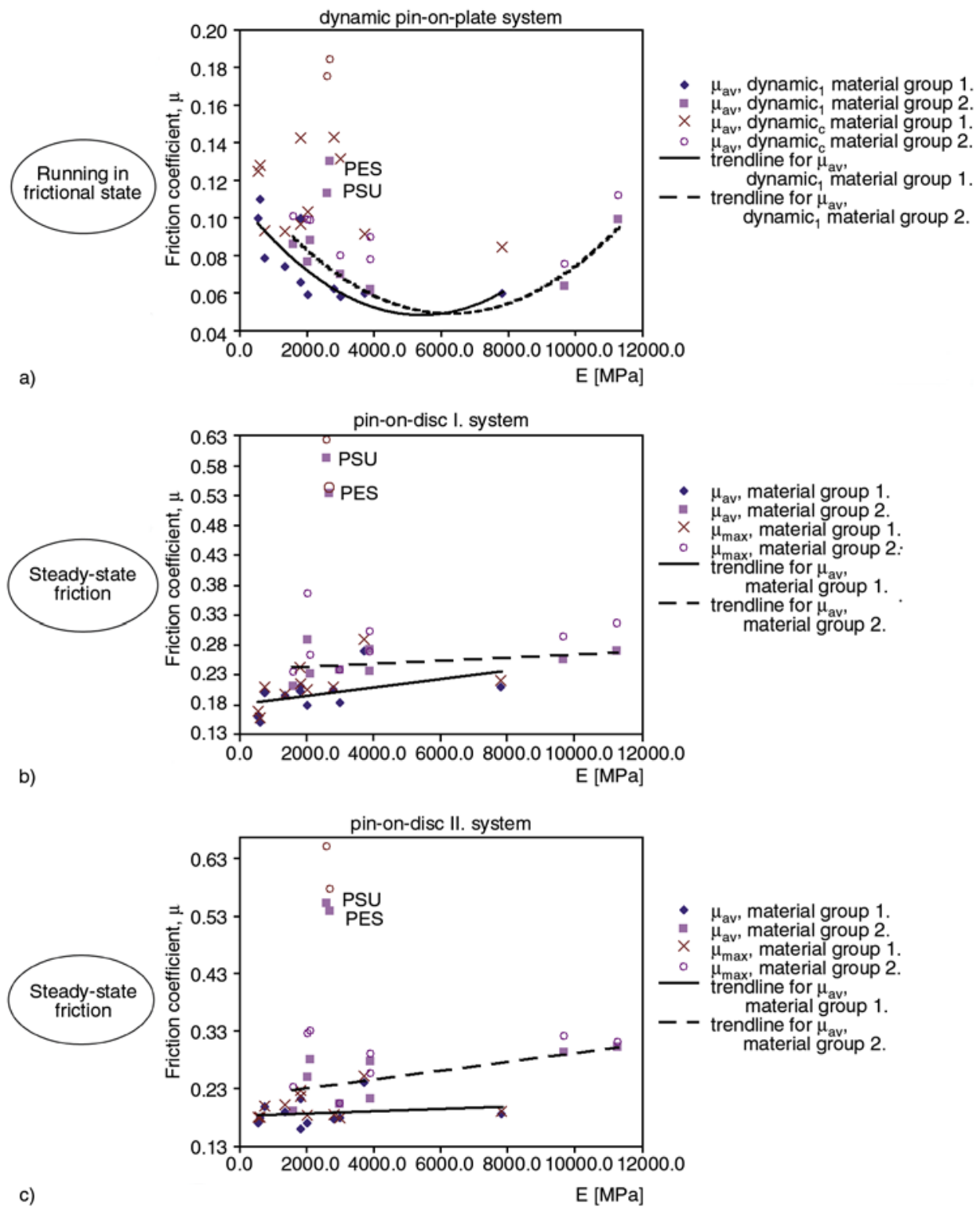

Figure 11. Friction coefficients versus Young's modulus, $E$ [MPa]. (a) dynamic pin-on-plate, cycle 1 and completed program, $\mu_{\mathrm{av}}$ values, (b) pin-on-disc I $\left(p v=0,8 \mathrm{MPa} \cdot \mathrm{ms}^{-1}\right), \mu_{\max }$ and $\mu_{\mathrm{av}}$ values, (c) pin-on-disc II $\left(p v=2 \mathrm{MPa} \cdot \mathrm{ms}^{-1}\right)$, $\mu_{\max }$ and $\mu_{\mathrm{av}}$ values.

sion and surface energy of the plastics. Increasing the load (pin-on-disc II) modifies the effect (Figure 12c) of the hardness on the friction. In the case of material group 1, the plastics having a Shore D hardness of 80 or higher exhibited lower friction; those materials in the pin-on-disc I system worked in the zone to the left of the optimum point of friction (according to the friction theory in Figure 3), but at higher loads, they worked in the zone closer to the optimum point. This was not the case for material group 2. Those plastics worked around the optimum point or in the zone to the right of the optimum point (in Figure 3 ) in the pin-on-disc I system, and at higher loads, they moved away from the optimum point to higher values.

\section{Conclusions}

Twenty-one different engineering polymers separated into three groups (semi-crystalline materials of sliding machine elements, semi-crystalline materials of load-carrying machine elements, and amorphous engineering plastics) were tested during both the running-in period and steady-state friction, and dynamic effects and different load levels ( $p v=0.8$ and $2 \mathrm{MPa} \cdot \mathrm{ms}^{-1}$ at steady state friction) were applied according to plastic engineering practices. Using 


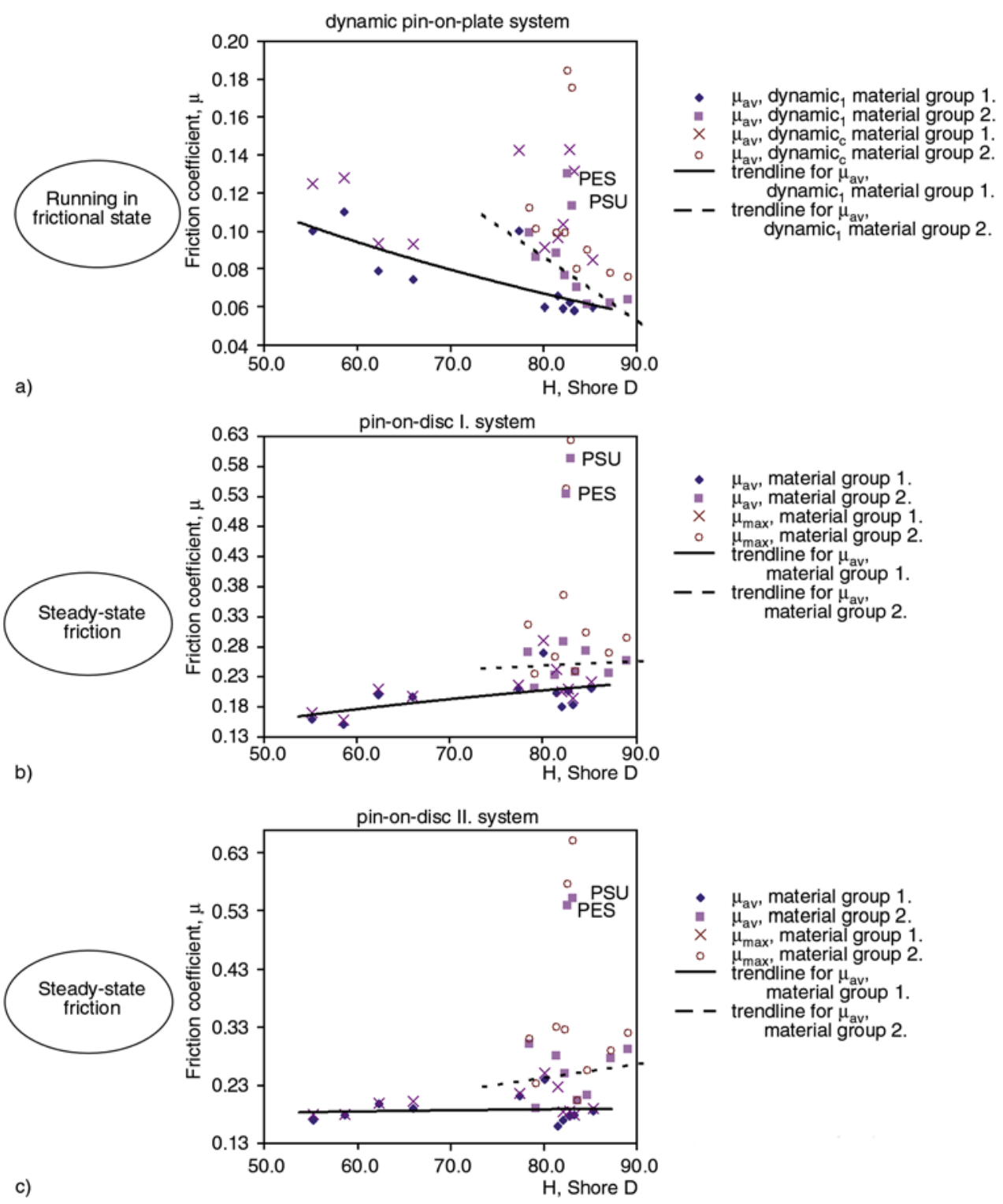

Figure 12. Friction coefficients versus Shore D hardness. (a) dynamic pin-on-plate, cycle 1 and completed program, $\mu_{\mathrm{av}}$ values, (b) pin-on-disc I ( $\left.p v=0,8 \mathrm{MPa} \cdot \mathrm{ms}^{-1}\right), \mu_{\max }$ and $\mu_{\mathrm{av}}$ values, (c) pin-on-disc II $\left(p v=2 \mathrm{MPa} \cdot \mathrm{ms}^{-1}\right), \mu_{\max }$ and $\mu_{\mathrm{av}}$ values.

pin-on-plate and pin-on-disc test rigs, the dry friction coefficient against a ground structural steel surface was determined. The data were evaluated as a function of various mechanical properties. In the test systems (engineering modelling applications), the following relationships were found:

- During the running-in period, the friction coefficient decreased with increasing yield stress and Shore D hardness. Friction increased with higher elongation at the break. $\mu$ had an optimum point (minimum) as a function of Young's modulus.

- During steady state friction under the lower load value the following relationships were found:

- Friction increased with increasing yield stress, Young's modulus, Shore D hardness, and the effect of the mechanical properties on friction was stronger for material group 1 (sliding materials) than for material group 2.

- Friction decreased with increasing elongation at break for the sliding material group, but no significant effect was found for the load-carrying material group.

- At the elevated load level $\left(p v=2 \mathrm{MPa} \cdot \mathrm{ms}^{-1}\right)$ in the pin-on-disc system, the following friction changes resulting from the effects of the deformation and adhesion components were observed:

- In the sliding material group, the mechanical properties showed no significant effects on friction. 
- In the load-carrying material group, the elongation at the break had no effect on friction, while increasing the yield stress, Young's modulus and the Shore D hardness increased friction.

- The results from the amorphous PES and PSU materials showed poor friction performance. These materials cannot be compared to the semi- crystalline engineering plastics and are not recommended as structural materials supporting a frictional load.

\section{Acknowledgements}

Many thanks to L. Zsidai, R. Keresztes, M. Andó for their laboratory assistance and to Quattroplast Ltd. for supporting this research work.

\begin{tabular}{|c|c|}
\hline$\mu$ & Friction coefficient $[-]$ \\
\hline$F_{\mathrm{x}}, F$ & Measured friction force component $[\mathrm{N}]$ \\
\hline$R$ & Yield stress $[\mathrm{MPa}]$ \\
\hline$H$ & Shore D hardness [-] \\
\hline$A$ & Elongation at break [\%] \\
\hline$E$ & Modulus of elasticity [MPa] \\
\hline$p v$ & Data of friction system design of thermoplastics $\left[\mathrm{MPa} \cdot \mathrm{ms}^{-1}\right]$ \\
\hline$P$ & Normal load $[\mathrm{N}]$ \\
\hline$R_{\mathrm{a}}$ & Surface roughness $[\mu \mathrm{m}]$ \\
\hline PTFE & Unmodified Polytetrafluoroethylene \\
\hline PTFE/graphite & Polytetrafluoroethylene/graphite composite \\
\hline UHMW-PE HD500 & Unmodified Ultra-high-molecular-weight polyethylene, grade HD500 \\
\hline UHMW-PE HD1000 & Unmodified Ultra-high-molecular-weight polyethylene, grade HD1000 \\
\hline PA 4.6 & Unmodified Polyamide 4.6 \\
\hline PA6E & Unmodified extruded Polyamide 6 \\
\hline PA6G(Mg) & Unmodified Magnesium catalytic cast Polyamide 6 \\
\hline PA6G(Mg)/oil & Magnesium catalytic cast Polyamide 6/oil composite \\
\hline $\mathrm{PA} 6 \mathrm{G}(\mathrm{Na}) / \mathrm{MoS}_{2}$ & Potassium catalytic cast Polyamide $6 / \mathrm{MoS}_{2}$ composite \\
\hline PA6G/PE & Potassium catalytic cast Polyamide 6/Polyethylene composite \\
\hline PA 66 GF30 & Polyamide 66/glass fibre composite \\
\hline PETP & Unmodified Polyethylene terephthalate \\
\hline PETP TF & Polyethylene terephthalate/Polytetrafluoroethylene composite \\
\hline POM C & Unmodified Polyoxymethylene copolymer \\
\hline PPS HPV & Polyphenylene sulphide/glass fibre, oil composite \\
\hline PSU & Unmodified Polysulfone \\
\hline PES & Unmidufued Polether sulfone \\
\hline PVDF & Unmodified Polyvinylidene fluoride \\
\hline PEEK & Unmodified Polyether ether ketone \\
\hline PEEK GF & Polyether ether ketone/glass fibre composite \\
\hline PEEK Mod & Polyether ether ketone/carbon fibre, Polytetrafluoroethylene, graphite composite \\
\hline
\end{tabular}

\section{References}

[1] Bhushan B.: Modern tribology handbook. Vol. 1-2. CRC Press, Boca Raton (2001).

[2] Zum Gahr K-H.: Microstructure and wear of materials. Elsevier, Amsterdam (1987).

[3] Hutchings I. M.: Tribology: Friction and wear of engineering materials. Edward Arnold, London (1992).

[4] DIN 50322: Wear. Wear testing categories (1986).

[5] Yamaguchi Y.: Tribology of plastic materials. Elsevier, Amsterdam (1990).

[6] Böhm H., Betz S., Ball A.: The wear resistance of polymers. Tribology International, 23, 399-406 (1990). DOI: $10.1016 / 0301-679 X(90) 90055-\mathrm{T}$
[7] Czichos H., Klaffke D., Santner E., Woydt M.: Advances in tribology: The materials point of view. Wear, 190, 155-161 (1995).

DOI: 10.1016/0043-1648(96)80014-7

[8] Santner E., Czichos H.: Tribology of polymers. Tribology International, 22, 103-109 (1989).

DOI: $10.1016 / 0301-679 X(89) 90170-9$

[9] Rajesh J. J., Bijwe J., Tewari U. S.: Abrasive wear performance of various polyamides. Wear, 252, 769-776 (2002).

DOI: 10.1016/S0043-1648(02)00039-X 
[10] Tewari U. S., Bijwe J., Mathur J. N., Sharma I.: Studies on abrasive wear of carbon fibre (short) reinforced polyamide composites. Tribology International, 25, 5360 (1992). DOI: 10.1016/0301-679X(92)90121-3

[11] Keresztes R., Kalácska G., Zsidai L., Eberst O.: Abrasive wear of polymer-based agricultural machine elements in different soil types. Cereal Research Communications, 36, 903-907 (2008).

[12] Arribas A., Bermúdez M-D., Brostow W., CarriónVilches F. J., Olea-Mejía O.: Scratch resistance of a polycarbonate + organoclay nanohybrid. Express Polymers Letters, 3, 621-629 (2009).

DOI: $10.3144 /$ expresspolymlett.2009.78

[13] Unal H., Findik F.: Friction and wear behaviours of some industrial polyamides against different polymer counterparts under dry conditions. Industrial Lubrication and Tribology, 60, 195-200 (2008). DOI: $10.1108 / 00368790810881542$

[14] Byett J. H., Allen C.: Dry sliding wear behaviour of polyamide 66 and polycarbonate composites. Tribology International, 25, 237-246 (1992). DOI: 10.1016/0301-679X(92)90061-Q

[15] Kato K.: Wear in relation to friction - A review. Wear, 241, 151-157 (2000). DOI: 10.1016/S0043-1648(00)00382-3

[16] Khan M. S., Franke R., Gohs U., Lehmann D., Heinrich G.: Friction and wear behaviour of electron beam modified PTFE filled EPDM compounds. Wear, 266, 175-183 (2009).

DOI: $10.1016 /$ j.wear.2008.06.012

[17] Myshkin N. K., Petrokovets M. I., Kovalev A. V.: Tribology of polymers: Adhesion, friction, wear, and masstransfer. Tribology International, 38, 910-921 (2005). DOI: $10.1016 /$ j.triboint.2005.07.016
[18] Xu D., Karger-Kocsis J., Schlarb A. K.: Rolling wear of EPDM and SBR rubbers as a function of carbon black contents: Correlation with microhardness. Journal of Materials Science, 43, 4330-4339 (2008). DOI: $10.1007 / \mathrm{s} 10853-008-2637-7$

[19] Khan M. S., Lehmann D., Heinrich G., Gohs U., Franke R.: Structure-property effects on mechanical, friction and wear properties of electron modified PTFE filled EPDM composite. Express Polymers Letters, 3, 39-48 (2009).

DOI: $10.3144 /$ expresspolymlett.2009.7

[20] Brostow W., Dutta M., de Souza J. R., Rusek P., de Medeiros A. M., Ito E. N.: Nanocomposites of poly (methyl methacrylate) (PMMA) and montmorillonite (MMT) Brazilian clay: A tribological study. Express Polymers Letters, 4, 570-575 (2010).

DOI: $10.3144 /$ expresspolymlett.2010.71

[21] Kalácska G., Zsidai L., Keresztes R., Tóth A., Mohai M., Szépvölgyi J.: Effect of nitrogen plasma immersion ion implantation of polyamide- 6 on its sliding properties against steel surface. Wear, 290-291, 66-73 (2012).

DOI: 10.1016/j.wear.2012.05.011

[22] Keresztes R.: Tribology research of polymer/steel gear pairs. $\mathrm{PhD}$ thesis (in Hungarian). Szent István University, Gödöllö (2009).

[23] Bowden F. P., Tabor D.: Friction and lubrication of solids. Oxford University Press, London (1954).

[24] Samyn P., Kalacska G., Keresztes R., Zsidai L., De Baets P.: Design of a tribotester for evaluation of polymer components under static and dynamic sliding conditions. Proceedings of the Institution of Mechanical Engineers Part J: Journal of Engineering Tribology, 221, 661-674 (2007). DOI: $10.1243 / 13506501 J E T 266$ 